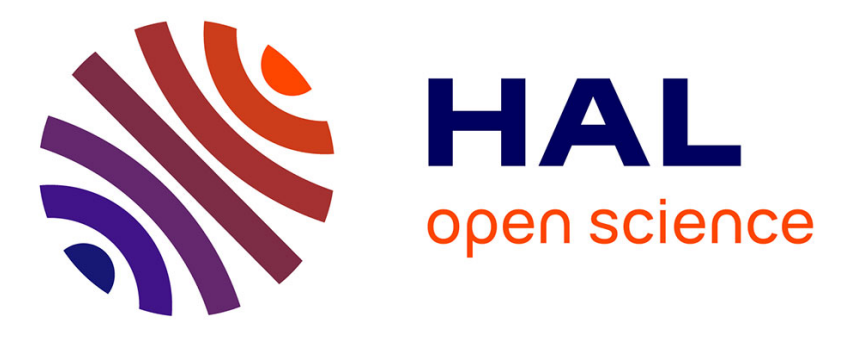

\title{
Worker thelytoky allows requeening of orphaned colonies but increases susceptibility to reproductive cheating in an ant
}

Claudie Doums, Pierre Federici, Pascaline Chifflet-Belle, Thibaud Monnin

\section{- To cite this version:}

Claudie Doums, Pierre Federici, Pascaline Chifflet-Belle, Thibaud Monnin. Worker thelytoky allows requeening of orphaned colonies but increases susceptibility to reproductive cheating in an ant. Animal Behaviour, 2018, 135, pp.109-119. 10.1016/j.anbehav.2017.11.013 . hal-01730713

\section{HAL Id: hal-01730713 https://hal.sorbonne-universite.fr/hal-01730713}

Submitted on 13 Mar 2018

HAL is a multi-disciplinary open access archive for the deposit and dissemination of scientific research documents, whether they are published or not. The documents may come from teaching and research institutions in France or abroad, or from public or private research centers.
L'archive ouverte pluridisciplinaire HAL, est destinée au dépôt et à la diffusion de documents scientifiques de niveau recherche, publiés ou non, émanant des établissements d'enseignement et de recherche français ou étrangers, des laboratoires publics ou privés. 
1 Worker thelytoky allows requeening of orphaned colonies but increases susceptibility to

2 reproductive cheating in an ant

3

4

5 Claudie Doums ${ }^{12}$, Pierre Fédérici ${ }^{3}$, Pascaline Chifflet-Belle ${ }^{12}$, Thibaud Monnin ${ }^{3}$

6

$7{ }^{1}$ Institut de Systématique, Evolution et Biodiversité, UMR 7205, EPHE, CNRS, MNHN,

8 UPMC Univ Paris 06, Sorbonne Universités, Paris, France

$9 \quad{ }^{2}$ PSL Research University, EPHE, Paris, France

$10{ }^{3}$ Institute of Ecology and Environmental Sciences of Paris UMR 7618, CNRS, Sorbonne

11 Universités, UPMC Univ Paris 06, Paris, France

12

13

14 Corresponding author: Claudie Doums

15 ISYEB, UMR 7205 (CNRS MNHN UPMC EPHE)

16 Muséum National d'Histoire Naturelle, CP39

17 Bât. Cryptogamie, 12 rue Buffon, 75005 Paris, France

$18 \quad$ Tel: $+33(0) 140798037$

19 Email: claudie.doums@ephe.sorbonne.fr

20

21 Word count: 7304 words (all included)

22 


\section{ABSTRACT:}

In some social insects workers can produce females asexually through thelytokous parthenogenesis. This allows them to produce replacement queens (i.e. requeening) if the queen has died, but also to compete with the queen for producing females (i.e. reproductive cheating). For the first time, we experimentally tested the role of worker thelytoky under quasi-natural conditions in the ant Cataglyphis cursor, where the queen uses both sexual and thelytokous reproduction. We reared pairs of orphaned and queenright colonies in enclosures for almost three months, during which they competed for resources. Orphaned colonies lost more workers than queenright colonies over the course of the experiment, presumably because of the costs of reproductive conflicts between workers. Nevertheless, they produced new queens through worker thelytoky and new colonies through colony fission. This is the first unambiguous demonstration that worker thelytoky allows requeening under natural conditions in this species. We further show that worker thelytoky results in reproductive cheating in the form of a few workers reproducing in presence of the queen (in queenright colonies) and of a few worker lineages producing more new queens than other lineages (in orphaned colonies). In addition, it also results in rare instances of social parasitism i.e. workers entering and reproducing in foreign colonies. These benefits to workers seem too occasional and too low to drive the evolution of theytoky in this species. We argue that thelytoky likely evolved in the queen caste, where it allows producing young queens and confers frequent and massive benefits by increasing gene transmission, but is also expressed in workers because of genetic correlations between the two castes.

Keywords: Cataglyphis cursor, cheating, cost of reproduction, thelytoky, social insects, worker reproduction 
Cooperative systems are exposed to the apparition of selfish elements that benefit from the common goods without paying the costs arising from their production (Chapuisat, 2009; Dobata \& Tsuji, 2013; Hughes \& Boomsma, 2008). By doing so, cheaters increase their fitness and decrease that of the other individuals. Cheating has evolved in a range of cooperative organisms, from bacteria to mammals (Ghoul, Griffin, \& West, 2014; Riehl \& Frederickson, 2016). In social hymenoptera, workers typically rear the offspring of their mother queen instead of their own, yet a low level of worker reproduction in presence of the queen (i.e. cheating) has been observed in various species (Barron, Oldroyd, \& Ratnieks, 2001; Bourke, 2011; Ratnieks, Foster, \& Wenseleers, 2006; Ratnieks \& Wenseleers, 2008; Sundström \& Boomsma, 2001).

60

Because of the haplo-diploid sex determination system of hymenoptera, workers can potentially produce haploid sons (arrhenotoky) in most species (e.g. Ratnieks et al. 2006; Bourke 2011). However, worker policing (through oophagy and/or aggression) and selfrestraint usually lessen or even prevent intra-colonial cheating (Ratnieks, 1988; Ratnieks et al., 2006). In addition, colony recognition similarly limits or prevents intraspecific social parasitism, that is the reproduction of foreign workers (Beekman and Oldroyd 2008). Despite this, low levels of intra-colonial cheating have been observed in many species (Barron et al., 2001; Bourke, 2011; Ratnieks et al., 2006; Ratnieks \& Wenseleers, 2008; Sundström \& Boomsma, 2001), and reproduction by drifting workers has also been detected in several species (Chapman, Nanork, et al., 2009; Chapman, Beekman, \& Oldroyd, 2010; Chapman, 
Another, more subtle, form of cheating can occur when there are many patrilines

within a colony (i.e. the queen is mated with several males), given that patrilines that are more successful at producing queens are advantaged by individual selection. A differential success at queen production could be achieved by various ways. Patrilines may differ in their larval propensity to develop into queens, so that caste is partially determined by genetic variation among patrilines (Anderson, Linksvayer, \& Smith, 2008; Hughes \& Boomsma, 2008; Schwander, Lo, Beekman, Oldroyd, \& Keller, 2010). Workers may also preferentially rear larvae from their own patriline into queens. However, such nepotistic behaviours have rarely been detected, and have been subject to controversy when detected (Hannonen \& Sundström, 2003; Holzer, Kümmerli, Keller, \& Chapuisat, 2006; Reeve \& Keller, 1997; Tarpy, Gilley, \& Seeley, 2004). 84

Finally, patrilines may engage in direct reproductive competition when workers themselves are capable of producing new queens by thelytokous reproduction, as in some honey bees (Holmes, Tan, Wang, Oldroyd, \& Beekman, 2015; Verma \& Ruttner, 1983) and some thermophilic ants from the genus Cataglyphis (Aron, Mardulyn, \& Leniaud, 2016). Some patrilines may gain a disproportionately higher reproductive success than others either because a higher fraction of their workers are reproducing or because they are more fecund (Goudie et al., 2012). The selective pressure for the evolution of cheating is more pronounced when workers are able to produce females, because a worker that manages to produce the new queen in some way reincarnates herself into that queen (Greeff, 1996). Quite surprisingly, and although thelytokous reproduction has evolved independently in many social insect species (Wenseleers \& Van Oystaeyen, 2011), worker thelytoky in queenright colonies has been observed in only two species, the Cape honey bee A. m. capensis (Goudie and Oldroyd 2014 for a review and references therein) and the ant $C$. cursor (Doums, Ruel, et al., 2013). In the 
Cape honey bee, reproductive workers can be considered cheaters in queenright colonies where they produce up to $60 \%$ of new queens (Allsopp, Beekman, Gloag, \& Oldroyd, 2010; Jordan, Allsopp, Oldroyd, Wossler, \& Beekman, 2008) whereas in C. cursor, the use of thelytoky by workers is less clear (Chéron, Monnin, Fédérici, \& Doums, 2011; Doums, Ruel, et al., 2013). In addition, worker thelytoky may also confer benefits from intra-specific social parasitism, and indeed social parasitism has been observed in several species with thelytokous workers (Allsopp et al., 2010; Dobata et al., 2011; Moritz, Lattorff, Crous, \& Hepburn, 2011). In the Cape honey bee, workers enter foreign colonies where they produce 6 to $62 \%$ of queens (Härtel, Neumann, Raassen, Moritz, \& Hepburn, 2006; Moritz et al., 2011). One clonal worker lineage has even been found to parasitize a closely related subspecies, $A . m$. scutellata_where it behaves like pseudo-queens (reviewed in Goudie and Oldroyd 2014).

In social insects, the main force preventing the evolution of high levels of cheating is thought to be the costs of worker reproduction and of conflicts over reproduction, even though experimental evidences of such costs are scarce (Bourke, 2011; Ratnieks et al., 2006). Two studies in queenless ants showed a direct energetic cost (Gobin et al., 2013), and a cost on worker immune defence and on the time spent by workers to perform collective tasks (Bocher, Doums, Millot, \& Tirard, 2008). Species with worker thelytoky are similar to queenless ants in that after the death (or experimental removal) of the reproductive individuals, all workers have the potential to produce diploid eggs. This can generate intense conflicts over reproduction, but it can also provide the major benefit of avoiding colony death following the loss of the reproductive individual. Indeed, in most monogynous species, the death of the queen induces the rearing of new queens from the young diploid brood already present in the colony and the production of male by workers through arrhenotoky (Bourke, 2011). When no young diploid brood is available, the colony is hopelessly queenless and dies 
gradually after a bunch of male production. By allowing requeening of orphaned colonies, worker thelytoky can avoid colony death even when no brood is present (Holmes et al., 2010).

In this study, we investigated the level of intra- and inter-colonial worker reproduction in the ant $C$. cursor and tested the capacity of queenless colonies to requeen in spite of a potential cost of reproductive conflicts between workers. To do so, we orphaned colonies at the end of the hibernation period and let them compete with queenright colonies in quasinatural conditions until the time of sexual production. In C. cursor, the queen combines or alternates thelytokous and sexual reproduction to produce new queens (called "gynes" before they mate and start their own colony), but she only uses sexual reproduction to produce workers (Doums, Cronin, et al., 2013; Pearcy, Aron, Doums, \& Keller, 2004). Workers from orphaned colonies kept under laboratory conditions use thelytokous reproduction to produce gynes at the end of the hibernation period, and to produce workers later in the season (Cagniant, 1980; Chéron, Monnin, et al., 2011; Clémencet, Rome, Fédérici, \& Doums, 2008). Worker-produced gynes mate and monogyny is then restored by the killing of all but one gyne. Theoretically, a colony could hence be immortal since workers allow both colony growth and colony requeening. However, the extent of worker reproduction in the field is unknown.

First, we measured queen production in orphaned colonies, as evidence of their capacity to requeen, and compared the rate of worker survival of orphaned and queenright colonies under competition. Queenless colonies may suffer dramatic reduction of colony efficiency because of the costs associated with the massive worker reproduction, such as agonistic interactions, oophagy and lowered investment in foraging and colony maintenance tasks (Bocher et al., 2008; Clémencet et al., 2008; Malka, Shnieor, Katzav-Gozansky, \& 
148 Hefetz, 2008; Miller \& Ratnieks, 2001). We therefore expected a lower worker survival rate

149 in orphaned than in queenright colonies.

Second, we tested for the occurrence of cheating lineages in both orphaned and

152 queenright colonies. In orphaned colonies, we compared the paternity frequencies in workers

153 and gynes. Differential reproductive successes of patrilines would result in a discrepancy

154 between these two frequencies. Under laboratory conditions, a previous study show that some

155 patrilines produced significantly higher fractions of gynes than as expected according to their

156 frequencies among workers, suggesting that they had a higher reproductive success than the

157 other patrilines and that the frequency of cheating lineages was low (Chéron, Monnin, et al.,

158 2011). However, new queens were collected at the pupal stage and it thus remains possible

159 that cheating behaviours could take place at a later developmental stage, such as by selective

160 killing of new queens from other patrilines, and thus possibly result in more pronounced

161 differential success of competing patrilines and higher levels of cheating. On the other hand,

162 contrary to laboratory settings, selective killing of brood could be avoided in natural nests by

163 physically separating brood of different patrilines. In our experiment, we determined in

164 queenright colonies whether some gynes had been produced by workers instead of by the

165 queen. In previous studies, no worker-produced gynes had been detected among more than

166200 gynes produced by queenright colonies in the field (Doums, Cronin, et al., 2013).

167 However, some diploid males had been produced by worker thelytoky in queenright colonies,

168 showing that some workers attempted to reproduce in presence of the queen (Doums, Ruel, et

169 al., 2013). 
Third, because orphanage may be a time of fragility with weakened colony integrity,

172 we checked whether drifting occurred and whether drifting workers reproduced, as suggested

173 in a previous study (Chéron, Monnin, et al., 2011).

174

175

176

177

178

179

180

181

182

183

184

185

186

187

188

189

190

191

192

193

194

195

Colony collection and experiment

\section{MATERIAL AND METHODS}

At the end of the hibernation period ( $8^{\text {th }}$ to $10^{\text {th }}$ March 2011$), 18$ colonies were completely excavated in the population of Argelès-sur-Mer near Perpignan $\left(42.5722^{\circ} \mathrm{N}, 3.0437^{\circ} \mathrm{E}\right)$. They contained an average of 961.8 workers (range: 427-2101) and no brood (Table A1). Two of these colonies were collected with no queen. Whether the queen died during hibernation or was lost during excavation is unclear. Colonies were then paired by colony size, with each pair comprising one queenright and one queenless colony (either collected with no queen or experimentally orphaned). Workers from colonies collected queenless should not behave differently than workers from experimentally orphaned colonies because eggs laying had not started at the time of collection. Removed queens were stored in 90\% Ethanol (10\% TE). The queen of queenright colonies was marked with a dot of paint (UniPaint marker, Mitsubishi pencil Co Ltd) and returned to its colony.

Colonies were transplanted into experimental enclosures located at the Mediterranean Garden of Mas de la Serre $\left(42.4740^{\circ} \mathrm{N}, 3.1161^{\circ} \mathrm{E}\right)$ in Banyuls-sur-mer, i.e. $12.5 \mathrm{Km}$ from their population of origin. Paired colonies were installed in the same enclosure (i.e. one pair of colonies per enclosure) as described in Cronin et al. (2012). Enclosures were $10.8 \mathrm{~m}^{2}$ in 
area. They consisted of a circular, vertical, metal chamber $1 \mathrm{~m}$ high filled to a height of

197 approximately $0.5 \mathrm{~m}$ with a 1:1 sand:earth mix (see details in Cronin et al. 2012). Enclosures

198 have the same number than in Cronin et al. (2012), and enclosure \#7 was not used.

Colonies were recovered from the enclosure at the time of sexual production $\left(23^{\text {rd }}\right.$ to $29^{\text {th }}$ of May 2011). In C. cursor, colony fission (i.e. the founding of new colonies by queens with the help of workers) takes place soon after sexual production (Chéron, Cronin, et al., 2011; Lenoir, Quérard, Pondicq, \& Berton, 1988). We timed the collect of colonies to maximize the probability that most sexuals would have emerged or be sufficiently advanced in their development to be sexed by dissection of large cocoons. At the same time, we paid attention to collect colonies before monogyny was restored (i.e. before all but one gynes were killed) to avoid losing gynes necessary for genetic analyses. Although we were largely successful and indeed collected a large number of sexuals, colony fission had started in five of nine enclosures (Figure 1). All nests except one (the queenright nest in enclosure 2) were fully excavated, and we censored the number of workers, gynes, males and large cocoons (i.e. cocoons of sexual). Large cocoons were opened and all were at the pupal stage and could be sexed by morphology. In enclosure 2, the nest with the marked queen not found in May was discovered in September, when we checked the enclosure for another purpose. The nine marked queens were therefore eventually all recovered. Colonies are identified by the number of the enclosure followed by QR or QL for queenright and queenless (orphaned) colonies, respectively, and a letter identifying colonies that were initially transplanted in the enclosure (a) and new colonies that they produced by fission (b to d). For instance, 1-QR-a and 1-QL-b design the queenright colony initially transplanted in enclosure 1 and a new colony produced by fission of the orphaned colony of enclosure 1 , respectively. 
The queenright colony could be identified by the presence of the marked queen in all enclosures, but when more than one queenless nest was recovered their origin was uncertain.

Queenless nests from the five enclosures where fission had started were assigned to either the queenright or the orphaned colony using the genotypes of two workers per nest (see below genetic analysis).

The ratio of workers lost during the course of the experiment was compared between orphaned and queenright colonies using a non parametric Wilcoxon paired test. Colonies were paired by enclosure to control for potential differential success among enclosures (Cronin et al. 2012). Given that there is no hibernating brood and that worker emergence only starts at the time or just after sexual production, colonies can only lose workers between March (time of transplantation) and May (time of collection). We calculated the ratio of workers lost as the difference in worker number between March and May divided by the number of worker in March. When a colony had fissioned into several nests, we pooled the nests belonging to the same colony (identified through the genetic analysis above) to obtain colony size in May and reproductive success.

We compared sexuals production by orphaned and queenright colonies after parentage

241 identification of sexuals (see genetic analysis below) using a Wilcoxon paired test. As for the 242 ratio of workers lost, we pooled the sexuals from newly founded nests with those from the 243 corresponding mother colony. To determine the number of males produced, we removed the 244 foreign males identified by the genetic analysis (see below) from the number of males 245 collected. 
Note that for enclosure 2, the queenright nest was not found in May but was collected

247 a few months later as explained above, hence enclosure 2 was removed to perform the

248 Wilcoxon paired tests.

Genetic analysis

252 To identify the mode of reproduction and the colony of origin of sexuals, we genotyped the queens of experimentally orphaned $(n=7)$ and queenright $(n=9)$ colonies and all sexuals collected (males: 128 adults and 29 pupae dissected out of large cocoons; gynes: 349 adults and 56 pupae) at 8 microsatellites (Doums, Cronin, et al., 2013; Pearcy, Clémencet,

Chameron, Aron, \& Doums, 2004) (multiplex 6: cc51, cc58, cc65, cc100 and multiplex 7: cc61, cc11, cc46, cc99). In each enclosure, we genotyped around 20 workers from the queenless nest that produced the more gynes, which was likely to be the transplanted orphaned colony, to compare patrilines distribution in workers and gynes. For enclosure 4, we also genotyped 20 workers from the queenright nest because the results showed that three of

261 its ten gynes were produced by workers from the paired orphaned colony (see Results). We 262 also genotyped two workers from each smaller queenless nests, which were likely to be newly 263 founded nests, to assign them to either the initial orphaned or queenright colony as their 264 mother colony (see below). A total of 806 individuals were thus genotyped (16 queens, 227 265 workers, 157 males and 405 female sexuals, Table A1).

DNA was extracted from the head (half of the head for gynes) of each individual in $500 \mu \mathrm{L}$ of Chelex $10 \%$ with $20 \mu \mathrm{L}$ of protein $\mathrm{K}$. The samples were incubated for $4 \mathrm{~h}$ at $55^{\circ} \mathrm{C}$ followed by $15 \mathrm{~min}$ at $100^{\circ} \mathrm{C}$. After centrifugation, $20 \mu \mathrm{L}$ of supernatant was taken for

270 subsequent PCR. PCRs were carried out in a $10 \mu \mathrm{L}$ volume containing $1 \mu \mathrm{L}$ DNA solution 

(10-40 ng of DNA), $150 \mu \mathrm{M}$ of each dNTP, $100 \mathrm{nM}$ of each primer (except for Ccur65: 250 nM; Ccur99: 150 nM; Ccur100: $200 \mathrm{nM}$ ), 1X Taq buffer (with MgCl2 $1.5 \mathrm{mM}$ final) and 0.75 unit of Taq DNA polymerase (Q Biogen). Thermocycle conditions were as follows: 10 min at $94^{\circ} \mathrm{C}$ followed by 10 amplification cycles at $94^{\circ} \mathrm{C}$ for $15 \mathrm{~s}, 52^{\circ} \mathrm{C}$ for $15 \mathrm{~s}, 72^{\circ} \mathrm{C}$ for $30 \mathrm{~s}, 20$ amplification cycles at $89^{\circ} \mathrm{C}$ for $15 \mathrm{~s}, 52^{\circ} \mathrm{C}$ for $15 \mathrm{~s}, 72^{\circ} \mathrm{C}$ for $30 \mathrm{~s}$ and a final elongation step of $10 \mathrm{~min}$ at $72^{\circ} \mathrm{C}$. Amplification products were loaded together on a 3500 Genetic Analyzer (Applied Biosystems) and allele sizes were estimated using GenMapper 4.0 software. A previous study detected no linkage disequilibrium or departure from Hardy-Weinberg equilibrium in the population studied (Doums, Cronin, et al., 2013).

We used the software Colony (Jones \& Wang, 2010) to assign workers to their mother queen (and subsequently assigned the queenless nests in the enclosure in which fission had started), determine worker patrilines and, for the two colonies that had been collected queenless, infer queen genotype. Colony was run assuming multiple mating by females, a medium prior with a paternal sibship of four and a maternal sibship of 20 . We provided the 16 available mother queens and assumed a probability of the mother being in these 16 queens of 0.9 (since two queens were missing). We were able to deduce the genotype of the mother queen for only one of the two colonies that had been collected queenless (nest 3-QL-a). Colony proposed up to eight mothers for the other queenless colony (nest 6-QL-a, see results) hence we did not use it for comparing patrilines distribution in workers and gynes.

\section{Origin and mode of production of gynes}

All gynes could unambiguously be identified as offspring of either the queen or workers of the queenright or orphaned colony, because these queens had at least four diagnostic loci 
(with no common alleles). The assignment was done manually because recombination during

297 thelytoky can lead to the transition from the heterozygous to the homozygous state (Pearcy et al. 2011 for queens, Chéron, Monnin, et al. 2011 for workers). Hence at some loci, a workerproduced gyne could be homozygous at a paternal allele and have no common allele with the mother queen. We therefore only used heterozygote loci to assign the gynes to one of the two 301 possible colonies. thelytokous reproduction of the mother queen, or by thelytokous reproduction of workers. We compared the genotype of gynes with those of the mother queen. If all alleles of a gyne were present in the queen, we concluded that the gyne had been produced parthenogenetically by the queen. When at least one locus of a gyne was heterozygous with one allele present in the mother queen and one allele not present in the mother queen, we concluded to sexual reproduction of the queen. For a few gynes, we observed a maternal or non-maternal allele at the homozygous state for one or two loci (see results) and concluded that the gyne had been

311 produced by thelytoky of a worker (see Doums, Cronin, et al. 2013 for additional

312 informations on the identification of worker produced gynes). In this last case, the PCR amplification was performed a second time to confirm the genotype.

\section{Origin of males}

317 In C. cursor, workers do not produce males in presence of the queen (Doums, Ruel, et al., 318 2013; Pearcy, Timmermans, Allard, \& Aron, 2009). We therefore considered that males 319 carrying one or more alleles absent in the queen were foreigners. To investigate further the 320 origin of foreign males, we tested whether they could be the offspring of one of the other 
queens from our enclosures using the software Colony. None of the 42 haploid foreign males

322 could be the offspring of a queen of our enclosures. Moreover, for six of the eight loci, the

323 allelic distribution was significantly different between the queens and the pool of foreign

324 males (fisher exact tests: $P=0.02$ (L46); $P=0.07$ (L51); $P<0.001$ (L11); $P<0.001$ (L58); $P$

$325=0.01(\mathrm{~L} 61) ; P<0.001$ (L99); $P<0.001$ (L100); $P=0.27$ (L65)). Given that genetic

326 differentiation can be very high even at the scale of few kilometres in this species (Clémencet

327 et al., 2005), it is very likely that the foreign males originated from colonies naturally

328 occurring in the vicinity of the enclosures.

Comparison of worker and gyne patrilines distribution in queenless nests

332 The genotypes of 201 workers were used for determining patrilines distribution in orphaned colonies and in the queenright colony of enclosure 4 using the software Colony.

Unfortunately, we could not consider nest 6-QL-a because it was collected queenless before the onset of the experiment and it was not possible to deduce the genotype of the queen from workers' genotypes (see above). We considered the diploid males as gynes since they are produced by thelytokous reproduction of workers (Doums, Ruel, et al., 2013).We determined the patrilines of the diploid males visually (see above). The distribution of paternity frequency was compared between workers and gynes using a Fisher exact test with the null hypothesis that there was no difference in patrilines distribution.

All statistical analyses were conducted using the R program (R Core Team, 2016) with RStudio (RStudio Team, 2016), and graphics were drawn with ggplot2 package (Wickham, 2009). 
RESULTS

Success of queenright and queenless colonies

At least two nests were found in each enclosure, and they matched the two colonies initially

transplanted in the enclosures. The process of colony fission had started at the time of colony

collection in five enclosures where more than two nests were recovered (Figure 1). Newly

founded nests contained fewer workers (median 56 workers, quartiles 40-103) and no or few gynes and hence could not be confounded with the two colonies initially transplanted, which were more populous (median 314 workers, quartiles 280-479) except for nest 8-QL-a (Figure

1). The genetic analysis of two workers from each of the 12 newly founded nests allowed to unambiguously assign them to their mother nest. Nine (75\%) originated from orphaned colonies can found new colonies by fission.

The ratio of workers lost during the 11 weeks spent in the enclosures varied from 0.32 to 0.68 (Figure 2a). Orphaned colonies lost a higher ratio of workers than paired queenright colonies in all but one enclosure, and overall worker loss was significantly higher for orphaned colonies (median of 0.58 vs. 0.41 , respectively, Wilcoxon paired test $: \mathrm{V}=2$, ddl $=$

$3667, \mathrm{p}=0.023 ;$ Figure 2a).

All orphaned colonies produced gynes, and these gynes were all thelytokous offspring of natal workers (i.e. workers that were themselves daughters of the mother queen that we experimentally removed or inferred). In C. cursor, worker thelytoky allows requeening in the laboratory (Cagniant, 1980; Chéron, Monnin, et al., 2011). This is the first unambiguous 
demonstration that it also allows requeening under semi-natural conditions and despite the presence of a queenright competitor colony.

We compared sexuals production by orphaned and queenright colonies after parentage identification of sexuals (see below). As for the ratio of workers lost, we pooled the sexuals from newly founded nests with those from the corresponding mother colony. A total of 405 gynes were produced, with $79 \%$ produced by orphaned colonies. All orphaned colonies produced gynes whereas less than half queenright colonies did (Figure 1). Six out of eight orphaned colonies produced more gynes than the paired queenright colony, even though this was marginally not significant (Wilcoxon paired test: $V=4$, $d d l=7, p=0.055$; Figure $2 b$ ). On the opposite, orphaned colonies produced only eight males and they were all diploid (see below), while two queenright colonies produced a total of 98 haploid males (57 and 41) (Figure 1).

Orphaned colonies that produced many sexuals experienced more worker reproduction and associated conflicts than colonies that produced few sexuals. If reproduction and conflicts are costly the former suffered a higher cost which may have resulted in a higher loss of workers. Supporting this idea, we found a positive significant correlation between the rate of worker loss and the number of sexuals produced in orphaned (Wilcoxon paired test, $\mathrm{P}=$ 0.004 ) but not in queenright colonies (Wilcoxon paired test, $\mathrm{P}=0.11$ ).

\section{Origin and mode of production of gynes}

Orphaned colonies produced numerous gynes (320) and all were thelytokously-produced by workers. In contrast, in the four queenright colonies that produced gynes most gynes were 
thelytokously-produced by the mother queen (72 out of the 85 gynes i.e. $85 \%$, including all gynes from nests 1-QR-a, 3-QR-a and 5-QR-a, Figure 1). The remaining 12 gynes were nonclonal and found in two nests. Two from the newly founded nest 3-QR-b were produced by worker thelytoky. However, it is unclear if these gynes were produced in presence of the queen. Indeed, nest 3-QR-b is a small new nest and it is possible that it had been founded by workers (by accidental colony fission) following the implantation of colonies in the enclosure. Ten non-clonal gynes were found in nest 4-QR-a. Five were likely worker-produced, two were either worker-produced or sexually-produced by the queen, and the remaining three were offspring of foreign workers (they had at least four heterozygote loci with no alleles in common with the mother queen, Table A2). It is telling that these three foreign gynes belonged to two patrilines (P1 and P3) found in the orphaned colony from the same enclosure (4-QL-a). This strongly suggests that worker drifting and intra-specific social parasitism had occurred, and this is corroborated by the finding that one of the 19 workers screened in queenright colony 4-QR-a also belonged to the same patriline (P1) from the orphaned colony. There is therefore little doubt that drifting occurred from the orphaned to the queenright 411 colony and was followed by reproduction, i.e. that social parasitism occurred.

\section{Origin of males}

416 Out of the 121 males found in queenright colonies, 15 could be considered as foreigners as 417 they had six to seven alleles different from those of the queen. Out of the remaining 106 males, one was diploid (nest 1-QR-a) and had a genotype similar to gynes, suggesting that it 
males were found in nests 1-QR-a, 2-QR-b and 8-QR-a and resulted from queen arrhenotoky

421 (Figure 1).

Far fewer males (36) were found in orphaned colonies. All haploid males (27) were

likely foreigners as they harboured one to eight alleles absent from workers. All these foreign males were adults and collected in nests producing gynes. Nine males were diploid, of which eight belonged to the same patrilines than gynes and could have been produced by worker thelytoky while the remaining one was probably a foreigner.

Comparison of worker and gyne patrilines distribution in queenless nests

A total of 201 workers were used to determine patriline distribution (nest 6-QL-a was excluded as the genotype of the mother queen could not be determined, see M\&M). All but two were offspring of the mother queen. One of these two foreign workers (in nest 8-QL-a) could not be the offspring of any of our sampled queens. The second foreign worker (in nest 4-QR-a) came from the orphaned colony of the same enclosure (nest 4-QL-a). The distribution of patrilines significantly differed between gynes and workers in three out of the eight colonies tested (Figure 3). In one of these three nests, most gynes belonged to patrilines not sampled in workers (Figure 3, nest 2-QL-a).

\section{DISCUSSION}

442 In many species of social insects, orphanage results in colony death. In others, the lost queen

443 is replaced and the colony carries on, yet orphanage is a crisis situation during which colony

444 functioning is disturbed and poor colony growth ensues. In addition, orphaned colonies are 
445 predicted to be particularly prone to reproductive conflicts in polyandrous species (Châline, 446 Arnold, Papin, \& Ratnieks, 2003; Chéron, Monnin, et al., 2011; Hughes \& Boomsma, 2008), 447 especially in species where workers can reproduce by thelytokous parthenogenesis (Greeff, 448 1996). Our experiment under semi-natural conditions shows that in the thelytokous ant $C$. 449 cursor, orphaned colonies lost a larger ratio of workers than queenright colonies, yet 450 produced many gynes as well as new incipient nests. This is to our knowledge the first 451 unambiguous demonstration that orphaned $C$. cursor colonies can requeen and fission under 452 quasi-natural conditions even though worker reproduction was costly. The results also suggest the occurrence of cheating patrilines at a low frequency, in both orphaned and queenright colonies, as well as the occurrence of intra-specific social parasitism, with some workers from one orphaned colony drifting into the paired queenright colony and producing gynes. Thelytokous worker reproduction allows requeening of colonies that become queenless during overwintering. However, orphaned colonies lost a larger ratio of workers than queenright colonies, suggesting that their functioning was impaired. It is likely that many workers attempted to produce gynes following orphanage and that this was costly. In the 461 laboratory, orphanage results in many workers laying eggs and the production of a huge amount of eggs (Cagniant, 1980; Clémencet et al., 2008). How the classic reproductive/survival trade-off (Harshman \& Zera, 2007; Stearns, 1992) applies at the individual level in social insect is not clear (Kramer, Schrempf, Scheuerlein, \& Heinze, 2015), 465 yet within the worker caste the high investment in reproduction may reduce survival.

466 Moreover, conflicts over reproduction may be costly at the colony level (Bocher et al., 2008; 467 Gobin, Heinze, Strätz, \& Roces, 2003). For instance, the time devoted to reproduction cannot 468 be used for colony maintenance and laying workers may avoid the risk of foraging outside 469 (Roth et al., 2014), which could lead to a lack of resources. Such ergonomic costs of worker 
reproduction are intuitive but hard to demonstrate (e.g. Bourke, 2011). Some indirect

471 evidence comes from the fact that colonies control worker reproduction in clonal species reproducing asexually, where worker reproduction has no genetic cost (Hartmann, Wantia,

473 Torres, \& Heinze, 2003; Teseo, Kronauer, Jaisson, \& Châline, 2013). Also, in another species

474 workers are not policed but refrain from reproducing in incipient colonies, presumably

475 because the ergonomic costs of worker reproduction would be prohibitively costly in such

476 small colonies (Moore \& Liebig, 2013). Direct costs of conflicts and of reproduction on

477 worker survival or on colony resources may therefore explain why orphaned colonies suffered 478 a higher worker loss than queenright colonies.

The number of new colonies that can be produced by colony fission is more limited by 481 the number of workers available than by the number of gynes (Cronin, Molet, Doums, 482 Monnin, \& Peeters, 2013). In $C$. cursor, colonies fission into $4.0 \pm 1.3$ (mean \pm SD) colonies 483 in the field (Chéron, Cronin, et al., 2011), or into $2.35 \pm 0.88$ colonies in our experimental 484 enclosures where competition for resources may be more severe owing to the limited space 485 (Cronin et al., 2012). In spite of this, orphaned colonies produced twice as many gynes in the current experiment (36 on average) than colonies fissioning in the field (14 on average, Doums, Cronin, et al. 2013). This suggests that they produced more gynes than as required for 488 requeening and colony fission. We argue that this is because worker thelytoky allows 489 requeening but also results in reproductive competition between workers, with the effect of an 490 excess production of gynes. Consequently, most gynes die when monogyny is restored in new 491 colonies, or else many new colonies are produced but they are small hence have reduced competitive abilities. Either way, the mass production of gynes appears non-optimal at the colony level for queenless colonies. This may be because of the conflict over reproduction 
between workers, or because selection for an efficient requeening strategy is too low which

495 could occur for instance if orphanage is rare.

Reproductive cheating occurred in three out of nine orphaned colonies, where some patrilines produced more gynes than their fair share. A similar proportion (3/13) had previously been observed under laboratory conditions and at an earlier pupal stage (Chéron,

500 Monnin, et al., 2011). Comparison of patriline distribution in workers and gynes is not 501 sufficient to clearly demonstrate cheating. Other factors such as differential survival of patrilines in workers (Clémencet et al., 2008) or queen turnover could also generate differences in patriline distribution. The latter probably occurs in nest 2-QL-a, where 14 patrilines were detected with clear difference between worker and gyne patrilines distribution.

Cheating is also suggested by the occurrence of worker reproduction in one queenright colony. These results are in apparent contrast with another study where workers produced no gyne in presence of the queen (all gynes were queen-produced, by sex or thelytoky, Doums,

508 Cronin, et al. 2013), even though attempts of worker reproduction nevertheless occurred as 509 revealed by the presence of worker-produced diploid males (Doums, Ruel, et al., 2013).

510 Interestingly, the queenright colony where workers reproduced was the only one with a higher 511 rate of workers loss than in the paired queenless colony (Figure 2, enclosure 4). This suggests 512 that worker reproductive conflicts may have occurred in this colony, as it did in queenless 513 colonies. Overall, our results thus suggest the occurrence of cheating at low frequencies, and 514 in both queenright and queenless contexts. This is expected on relatedness grounds because 515 the pattern of selection for gyne production through worker thelytoky parallels that for male 516 production in polyandrous species (Ratnieks, 1988; Wenseleers \& Ratnieks, 2006). Workers 517 are collectively not expected to reproduce because they are equally or more related to queen518 produced gynes (by sex, $\mathrm{r}=0.4$; by thelytoky, $\mathrm{r}=0.5)$ than to worker-produced gynes $(\mathrm{r}=0.4)$ 
519 (Doums, Cronin, et al., 2013). However, cheaters can occur at a low frequency because they

520 are more related to clonal female offspring of their patriline $(0.75)$ than to any other female

521 offspring (own patriline $>$ mother queen $>$ other patrilines). Because cheaters exploit the

522 benefits of cooperation they should increase in frequency, until they reach an equilibrium with

523 cooperators if the fitness of cheaters is negatively frequency dependent, or until they invade

524 the population and cooperation stops, at which points cheaters cease to exist as such as there

525 is no more sociality to exploit (Ghoul et al., 2014). Here, the benefits of cheaters are clearly

526 frequency dependent in regards of relatedness, and they would decrease if too many workers

527 were to reproduce. Consistently with this, the cheating lineages detected so far have always

528 been found to be rare in colonies and/or in populations (Härtel et al. 2006; Hughes and

529 Boomsma 2008; Chéron, Monnin, et al. 2011, this study). Another factor limiting the

530 frequency of cheaters is that they likely trade-off their investment in colony maintenance and

531 brood rearing towards reproduction (Roth et al., 2014). This cost may be negligible when

532 cheaters are rare but may become important if they increase in frequency. One factor that may

533 favour cheaters is that they may be more likely to engage in social parasitism than other

534 lineages, in which case they would provide some inclusive fitness to the other worker

535 patrilines.

Our experiment showed that workers from one orphaned colony (nest 4-QL-a) drifted

538 into the paired queenright colony (4-QR-a) where they produced gynes (Figure 1). This is the

539 first unambiguous demonstration of intra-specific social parasitism in C. cursor under natural

540 conditions, and it corroborates the finding of a previous study under laboratory conditions in

541 which foreign workers present in one colony produced a disproportionably high number of

542 gynes (Chéron, Monnin, et al., 2011). The drifting of workers into unrelated colonies is well

543 known in social insects, including in C. cursor (Chéron, Monnin, et al., 2011; Doums, Cronin, 
et al., 2013). However, it remains largely unclear whether it is an accidental phenomenon, as

545 in the thelytokous Cape honey bees (reviewed in Goudie and Oldroyd 2014), or an active 546 process, as in Bombus terrestris (Blacher et al., 2013). Orphaned colonies may be more 547 susceptible to social parasitism by foreign workers. They are weakened by the loss of many 548 workers and disorganised by the onset of worker reproduction, so that foreign workers may 549 succeed entering colonies more often. In addition, orphaned colonies stop policing worker 550 reproduction hence foreign workers that have succeeded entering the colony are more likely to reproduce unchecked. In our experiment, orphaned colonies did not suffer more from social parasitism as we found only one foreign worker in one of the nine orphaned colonies, which 553 is less than in the field where foreign workers occurred in 6 out of 13 colonies (Chéron, 554 Monnin, et al., 2011). This may be because colonies react to orphanage by tightening the 555 scrutiny of individuals entering the nest, as occurs in orphaned honeybee colonies that face a similar threat from social parasitism and respond by being more discriminatory against foreign workers (Chapman, Makinson, et al., 2009). Alternatively, orphaned colonies may be a source of social parasitic workers if the intense reproductive conflicts between workers result in some workers absconding or being expelled from the colony. That is, social

560 parasitism may be a side effect of the massive worker reproduction in orphaned colonies 561 rather than an evolved parasitic strategy (Blacher et al., 2013). Our data support this 562 hypothesis to some extent as we found gynes produced by workers from the orphaned colony 563 in one of the four queenright colonies that produced gynes (colony 4-QR-a). evolution of thelytokous parthenogenesis in this species. In general, thelytoky provides some benefits compared to sexual reproduction, such as the avoidance of the twofold cost of sex, a reproductive insurance under low population density and the maintenance of co-adapted gene 
pool (Bell, 1982; Hurst \& Peck, 1996; Meirmans, Meirmans, \& Kirkendall, 2012). These

570 benefits also occur in social organisms if the queen reproduces through thelytoky, but other 571 selective forces come into play when workers use thelytoky as in C. cursor. At the colony 572 level, worker thelytoky is beneficial by allowing requeening after the death of the queen

573 (Lenoir et al., 1988). Our results show that this factor could indeed play a role in C. cursor, 574 even though the frequency of colony orphanage is unknown. Queens are often replaced by 575 young queens during colony fission (Chéron, Cronin, et al., 2011) so we surmise that old queens may be relatively rare and hence orphanage may be relatively uncommon. Assuming that colonies collected queenless result from natural orphanage and not from the loss of the queen during collection, we can estimate an upper limit to the frequency of orphanage at the end of hibernation. Based on this paper and on two other field collections carried out in 580 March, we found 5.5\% of queenless colonies at collection (2/18 queenless colonies in 2011 581 (this paper); 0/13 in 2013; $1 / 19$ in 2015 (Doums \& Monnin, n.d.)). Whether worker thelytoky could allow requeening or survival of colonies that become orphaned at other times than early spring, when sexuals are produced, is unclear because gynes would remain virgin. Orphaned

584 colonies would thus have to produce the workers necessary for their survival by thelytoky (of 585 gynes and/or workers) until the next mating season, but the high worker loss experienced by 586 orphaned colonies in our experiment suggests this is unlikely. Therefore, the benefits obtained 587 by requeening may be insufficient to explain the evolution of worker thelytoky. At the 588 individual level, worker thelytoky may be favoured by the benefits obtained by cheating, 589 allowing workers to rewind the tape of social evolution in some ways (Gadagkar, 1997). 590 However, worker reproduction in presence of the queen and cheating patrilines in queenless 591 colonies are less frequent than in the Cape honey bees (Allsopp et al., 2010; Goudie \& 592 Oldroyd, 2014; Moritz et al., 2011). Ultimately, worker thelytoky may be better explained by 593 the benefits thelytoky confers to the queen caste (Doums, Cronin, et al., 2013; Pearcy, Aron, 
594 et al., 2004). Indeed, intercaste genetic correlations could constrain the evolution of queen-

595 worker dimorphism such that worker thelytoky may be a nonadaptive "caste load" from

596 positively selected thelytoky in queens (Holman et al 2013). More studies are required to

597 confirm the cost and benefits of thelytoky in both castes.

598 
600 Genetic analyses reported in this article can be reproduced using the data published in 601 Mendeley (doi:10.17632/83j7xtw6fm.2).

602

603

604 ACKNOWLEDGEMENTS

605 We thank the Laboratoire Arago (Observatoire Océanologique de Banyuls-sur-mer,

606 Université Pierre et Marie Curie) for permitting this study to take place on the experimental

607 grounds of the Mediterranean Garden of Mas de la Serre. We thank David Sillam-Dussès,

608 Fabien Aubrun, Romain Péronnet and Claire Tirard for helping in collecting colonies.

609

610

611

612 


\section{REFERENCES}

Allsopp, M. H., Beekman, M., Gloag, R. S., \& Oldroyd, B. P. (2010). Maternity of replacement queens in the thelytokous Cape honey bee Apis mellifera capensis. Behavioral Ecology and Sociobiology, 64(4), 567-574. http://doi.org/10.1007/s00265009-0872-9

Anderson, K. E., Linksvayer, T. A., \& Smith, C. R. (2008). The causes and consequences of genetic caste determination in ants (Hymenoptera : Formicidae). Myrmecological News, $11,119-132$.

Aron, S., Mardulyn, P., \& Leniaud, L. (2016). Evolution of reproductive traits in Cataglyphis desert ants: mating frequency, queen number, and thelytoky. Behavioral Ecology and Sociobiology, 70(8), 1367-1379. http://doi.org/10.1007/s00265-016-2144-9

Barron, A. B., Oldroyd, B. P., \& Ratnieks, F. L. W. (2001). Worker reproduction in honeybees (Apis) and the anarchic syndrome: A review. Behavioral Ecology and Sociobiology, 50(3), 199-208. http://doi.org/10.1007/s002650100362

Beekman, M., \& Oldroyd, B. P. (2008). When workers disunite: intraspecific parasitism by eusocial bees. Annual Review of Entomology, 53, 19-37. http://doi.org/10.1146/annurev.ento.53.103106.093515

Bell, G. (1982). The masterpiece of nature: the evolution and genetics of sexuality (CUP Archiv).

Blacher, P., Yagound, B., Lecoutey, E., Devienne, P., Chameron, S., \& Châline, N. (2013). Drifting behaviour as an alternative reproductive strategy for social insect workers. Proceedings of the Royal Society B: Biological Sciences, 280(1771), 20131888. http://doi.org/10.1098/rspb.2013.1888

Bocher, A., Doums, C., Millot, L., \& Tirard, C. (2008). Reproductive conflicts affect labor and immune defense in the queenless ant Diacamma sp. "nilgiri." Evolution, 62(1), 123- 
639 Bourke, A. F. G. (2011). Principles of social evolution. Oxford University Press.

640 Cagniant, H. (1980). La parthénogenèse thélytoque et arrhénotoque des ouvrières de la fourmi 641 Cataglyphis cursor Fonscolombe. Etude en élevage de la productivité de sociétés avec 642 reine et de sociétés sans reine. Insectes Sociaux, 27(2), 157-174.

643 Châline, N., Arnold, G., Papin, C., \& Ratnieks, F. L. W. (2003). Patriline differences in 644 emergency queen rearing in the honey bee, Apis mellifera. Insectes Sociaux, 50(3), 234236. http://doi.org/10.1007/s00040-003-0664-6

646

Chapman, N. C., Beekman, M., \& Oldroyd, B. P. (2010). Worker reproductive parasitism and drift in the western honeybee Apis mellifera. Behavioral Ecology and Sociobiology, 64(3), 419-427. http://doi.org/10.1007/s00265-009-0858-7

Chapman, N. C., Makinson, J., Beekman, M., \& Oldroyd, B. P. (2009). Honeybee, Apis mellifera, guards use adaptive acceptance thresholds to limit worker reproductive parasitism. Animal Behaviour, 78(5), 1205-1211. http://doi.org/10.1016/j.anbehav.2009.08.007

Chapman, N. C., Nanork, P., Gloag, R. S., Wattanachaiyingcharoen, W., Beekman, M., \& Oldroyd, B. P. (2009). Queenless colonies of the Asian red dwarf honey bee (Apis florea) are infiltrated by workers from other queenless colonies. Behavioral Ecology, 20(4), 817-820. http://doi.org/10.1093/beheco/arp065

Chapuisat, M. (2009). Social evolution: the smell of cheating. Current Biology, 19(5), R196R198. http://doi.org/10.1016/j.cub.2008.12.039

Chéron, B., Cronin, A. L., Doums, C., Fédérici, P., Haussy, C., Tirard, C., \& Monnin, T. (2011). Unequal resource allocation among colonies produced by fission in the ant Cataglyphis cursor. Ecology, 92(7), 1448-1458. http://doi.org/10.1890/10-2347.1

Chéron, B., Monnin, T., Fédérici, P., \& Doums, C. (2011). Variation in patriline reproductive 
success during queen production in orphaned colonies of the thelytokous ant Cataglyphis cursor. Molecular Ecology, 20(9), 2011-2022. http://doi.org/10.1111/j.1365294X.2011.05075.x

Clémencet, J., Rome, Q., Fédérici, P., \& Doums, C. (2008). Aggressions and size-related fecundity of queenless workers in the ant Cataglyphis cursor. Naturwissenschaften, 95(2), 133-139. http://doi.org/10.1007/s00114-007-0304-5

Cronin, A. L., Fédérici, P., Doums, C., \& Monnin, T. (2012). The influence of intraspecific competition on resource allocation during dependent colony foundation in a social insect. Oecologia, 168(2), 361-369. http://doi.org/10.1007/s00442-011-2098-6

Cronin, A. L., Molet, M., Doums, C., Monnin, T., \& Peeters, C. (2013). Recurrent evolution of Dependent Colony Foundation across eusocial Insects. Annual Review of Entomology, 58(1), 120830113030002. http://doi.org/10.1146/annurev-ento-120811-153643

Dobata, S., Sasaki, T., Mori, H., Hasegawa, E., Shimada, M., \& Tsuji, K. (2011). Persistence of the single lineage of transmissible "social cancer" in an asexual ant. Molecular Ecology, 20(3), 441-455. http://doi.org/10.1111/j.1365-294X.2010.04954.x

Dobata, S., \& Tsuji, K. (2013). Public goods dilemma in asexual ant societies. Proceedings of the National Academy of Sciences of the United States of America, 110(40), 1605616060. http://doi.org/10.1073/pnas.1309010110

Doums, C., Cronin, A. L., Ruel, C., Fédérici, P., Haussy, C., Tirard, C., \& Monnin, T. (2013). Facultative use of thelytokous parthenogenesis for queen production in the polyandrous ant Cataglyphis cursor. Journal of Evolutionary Biology, 26(7), 1431-1444. http://doi.org/10.1111/jeb.12142

Doums, C. \& Monnin, T. (n.d.). [Occurrence of queenless colonies in sampling collection of the ant Cataglyphis cursor]. Unpublished raw data.

Doums, C., Ruel, C., Clémencet, J., Fédérici, P., Cournault, L., \& Aron, S. (2013). Fertile 

Ecology and Sociobiology, 67(12), 1983-1993. http://doi.org/10.1007/s00265-013-16066

691 Gadagkar, R. (1997). Social evolution - has nature ever rewound the tape? Current Science, 72(12), 950-956.

Ghoul, M., Griffin, A. S., \& West, S. A. (2014). Toward an evolutionary definition of cheating. Evolution, 68(2), 318-331. http://doi.org/10.1111/evo.12266

Gobin, B., Heinze, J., Strätz, M., \& Roces, F. (2003). The energetic cost of reproductive conflicts in the ant Pachycondyla obscuricornis. Journal of Insect Physiology, 49(8), 747-752. http://doi.org/10.1016/S0022-1910(03)00111-2

Goudie, F., Allsopp, M. H., Beekman, M., Oxley, P. R., Lim, J., \& Oldroyd, B. P. (2012). Maintenance and loss of heterozygosity in a thelytokous lineage of honey bees (Apis mellifera capensis). Evolution, 66(6), 1897-1906. http://doi.org/10.1111/j.1558-

702 703 5646.2011.01543.x

Goudie, F., \& Oldroyd, B. P. (2014). Thelytoky in the honey bee. Apidologie, 45(3), 306-326. http://doi.org/10.1007/s13592-013-0261-2

Greeff, J. M. (1996). Effects of thelytokous worker reproduction on kin-selection and conflict in the Cape honeybee, Apis mellifera capensis. Philosophical Transactions of the Royal Society B: Biological Sciences, 351(1340), 617-625. http://doi.org/10.1098/rstb.1996.0060

Hannonen, M., \& Sundström, L. (2003). Sociobiology: Worker nepotism among polygynous ants. Nature, 421(6926), 910. http://doi.org/10.1038/421910a

Harshman, L. G., \& Zera, A. J. (2007). The cost of reproduction: the devil in the details. Trends in Ecology \& Evolution, 22(2), 80-86. http://doi.org/10.1016/j.tree.2006.10.008

Härtel, S., Neumann, P., Raassen, F. S., Moritz, R. F. A., \& Hepburn, H. R. (2006). Social 
parasitism by Cape honeybee workers in colonies of their own subspecies (Apis mellifera capensis Esch.). Insectes Sociaux, 53(2), 183-193. http://doi.org/10.1007/s00040-0050857-2

Hartmann, A., Wantia, J., Torres, J. A., \& Heinze, J. (2003). Worker policing without genetic conflicts in a clonal ant. Proceedings of the National Academy of Sciences of the United States of America, 100(22), 12836-12840. http://doi.org/10.1073/pnas.2132993100

Holmes, M. J., Oldroyd, B. P., Allsopp, M. H., Lim, J., Wossler, T. C., \& Beekman, M. (2010). Maternity of emergency queens in the Cape honey bee, Apis mellifera capensis. Molecular Ecology, 19(13), 2792-2799. http://doi.org/10.1111/j.1365294X.2010.04683.x

Holmes, M. J., Tan, K., Wang, Z., Oldroyd, B. P., \& Beekman, M. (2015). Genetic reincarnation of workers as queens in the Eastern honeybee Apis cerana. Heredity, 114(1), 65-68. http://doi.org/10.1038/hdy.2014.70

Holzer, B., Kümmerli, R., Keller, L., \& Chapuisat, M. (2006). Sham nepotism as a result of intrinsic differences in brood viability in ants. Proceedings of the Royal Society of London B: Biological Sciences, 273(1597), 2049-2052. http://doi.org/10.1098/rspb.2006.3553

Hughes, W. O. H., \& Boomsma, J. J. (2008). Genetic royal cheats in leaf-cutting ant societies. Proceedings of the National Academy of Sciences of the United States of America, 105(13), 5150-5153. http://doi.org/10.1073/pnas.0710262105

Hurst, L. D., \& Peck, J. R. (1996). Recent advances in understanding of the evolution and maintenance of sex. Trends in Ecology \& Evolution, 11(2), 46-52. http://doi.org/10.1016/0169-5347(96)81041-X

Jones, O. R., \& Wang, J. (2010). COLONY: A program for parentage and sibship inference from multilocus genotype data. Molecular Ecology Resources, 10(3), 551-555. 
http://doi.org/10.1111/j.1755-0998.2009.02787.x

739

740

741

742

743

744

745

746

747

748

749

750

751

752

753

754

755

756

757

758

759

760

761

762

Jordan, L. A., Allsopp, M. H., Oldroyd, B. P., Wossler, T. C., \& Beekman, M. (2008). Cheating honeybee workers produce royal offspring. Proceedings of the Royal Society of London B: Biological Sciences, 275(1632), 345-351. http://doi.org/10.1098/rspb.2007.1422

Kramer, B. H., Schrempf, A., Scheuerlein, A., \& Heinze, J. (2015). Ant colonies do not tradeoff reproduction against maintenance. PLoS ONE, 10(9), e0137969. http://doi.org/10.1371/journal.pone.0137969

Lenoir, A., Quérard, L., Pondicq, N., \& Berton, F. (1988). Reproduction and dispersal in the ant Cataglyphis cursor (Hymenoptera, Formicidae). Psyche, 95(1-2), 21-44. http://doi.org/10.1155/1988/54685

Malka, O., Shnieor, S., Katzav-Gozansky, T., \& Hefetz, A. (2008). Aggressive reproductive competition among hopelessly queenless honeybee workers triggered by pheromone signaling. Naturwissenschaften, 95(6), 553-559. http://doi.org/10.1007/s00114-008$0358-\mathrm{z}$

Meirmans, S., Meirmans, P. G., \& Kirkendall, L. R. (2012). The costs of sex: facing realworld complexities. The Quarterly Review of Biology, 87(1), 19-40. http://doi.org/10.1086/663945

Miller, D. G. I., \& Ratnieks, F. L. W. (2001). The timing of worker reproduction and breakdown of policing behaviour in queenless honey bee (Apis mellifera L.) societies. Insectes Sociaux, 48, 178-184. http://doi.org/10.1007/PL00001762

Moore, D., \& Liebig, J. (2013). Reproductive restraint without policing in early stages of a social insect colony. Animal Behaviour, 85(6), 1323-1328. http://doi.org/10.1016/j.anbehav.2013.03.022

Moritz, R. F. A., Lattorff, H. M. G., Crous, K. L., \& Hepburn, R. H. (2011). Social parasitism 

of queens and workers in the Cape honeybee (Apis mellifera capensis). Behavioral Ecology and Sociobiology, 65(4), 735-740. http://doi.org/10.1007/s00265-010-1077-y

Nanork, P., Chapman, N. C., Wongsiri, S., Lim, J., Gloag, R. S., \& Oldroyd, B. P. (2007). Social parasitism by workers in queenless and queenright Apis cerana colonies. Molecular Ecology, 16(5), 1107-1114. http://doi.org/10.1111/j.1365-294X.2006.03207.x

Pearcy, M., Aron, S., Doums, C., \& Keller, L. (2004). Conditional use of sex and parthenogenesis for worker and queen production in ants. Science, 306(5702), 17801783. http://doi.org/10.1126/science.1105453

771

772

773

774

775

776

777

778

779

780

781

782

783

Pearcy, M., Clémencet, J., Chameron, S., Aron, S., \& Doums, C. (2004). Characterization of nuclear DNA microsatellite markers in the ant Cataglyphis cursor. Molecular Ecology Notes, 4(4), 642-644. http://doi.org/10.1111/j.1471-8286.2004.00759.x

Pearcy, M., Hardy, O., \& Aron, S. (2011). Automictic parthenogenesis and rate of transition to homozygosity. Heredity, 107(2), 187-188. http://doi.org/10.1038/hdy.2010.172

Pearcy, M., Timmermans, I., Allard, D., \& Aron, S. (2009). Multiple mating in the ant Cataglyphis cursor: Testing the sperm limitation and the diploid male load hypotheses. Insectes Sociaux, 56(1), 94-102. http://doi.org/10.1007/s00040-008-1043-0

R Core Team. (2016). R: A language and environment for statistical computing. Vienna, Austria: R Foundation for Statistical Computing. Retrieved from https://www.rproject.org/.

Ratnieks, F. L. W. (1988). Reproductive harmony via mutual policing by workers in eusocial Hymeoptera. The American Naturalist, 132(2), 217-236. Retrieved from papers

Ratnieks, F. L. W., Foster, K. R., \& Wenseleers, T. (2006). Conflict resolution in insect societies. Annual Review of Entomology, 51, 581-608. http://doi.org/10.1146/annurev.ento.51.110104.151003

Ratnieks, F. L. W., \& Wenseleers, T. (2008). Altruism in insect societies and beyond: 
voluntary or enforced? Trends in Ecology \& Evolution, 23(1), 45-52. http://doi.org/10.1016/j.tree.2007.09.013

790

791

Reeve, H. K., \& Keller, L. (1997). Reproductive bribing and policing as evolutionary mechanisms for the suppression of within-group selfishness. The American Naturalist, 150(July), S42-S58. http://doi.org/10.1086/286049

Riehl, C., \& Frederickson, M. E. (2016). Cheating and punishment in cooperative animal societies. Philosophical Transactions of the Royal Society B, 371(1687), 20150090. http://doi.org/10.1098/rstb.2015.0090

Roth, K. M., Beekman, M., Allsopp, M. H., Goudie, F., Wossler, T. C., \& Oldroyd, B. P. (2014). Cheating workers with large activated ovaries avoid risky foraging. Behavioral Ecology, 25(3), 668-674. http://doi.org/10.1093/beheco/aru043

RStudio Team. (2016). RStudio: Integrated development for R. Boston, MA: RStudio, Inc. Retrieved from http://www.rstudio.com

Schwander, T., Lo, N., Beekman, M., Oldroyd, B. P., \& Keller, L. (2010). Nature versus nurture in social insect caste differentiation. Trends in Ecology \& Evolution, 25(5), 275282. http://doi.org/10.1016/j.tree.2009.12.001

Stearns, S. C. (1992). The evolution of life histories. Oxford University Press.

Sundström, L., \& Boomsma, J. J. (2001). Conflicts and alliances in insect families. Heredity, 86(5), 515-521. http://doi.org/10.1046/j.1365-2540.2001.00884.x

Tarpy, D. R., Gilley, D. C., \& Seeley, T. D. (2004). Levels of selection in a social insect: A review of conflict and cooperation during honey bee (Apis mellifera) queen replacement. Behavioral Ecology and Sociobiology, 55(6), 513-523. http://doi.org/10.1007/s00265003-0738-5

Teseo, S., Kronauer, D. J. C., Jaisson, P., \& Châline, N. (2013). Enforcement of reproductive synchrony via policing in a clonal ant. Current Biology, 23(4), 328-332. 
http://doi.org/10.1016/j.cub.2013.01.011

814 Verma, S., \& Ruttner, F. (1983). Cytological analysis of the thelytokous parthenogenesis in 815 the Cape honeybee (Apis mellifera capensis Escholtz). Apidologie, 14(1), 41-57.

816 Wenseleers, T., \& Ratnieks, F. L. W. (2006). Comparative analysis of worker reproduction

817 and policing in eusocial hymenoptera supports relatedness theory. The American

$818 \quad$ Naturalist, 168(6), E163-E179. http://doi.org/10.1086/508619

819 Wenseleers, T., \& Van Oystaeyen, A. (2011). Unusual modes of reproduction in social insects: Shedding light on the evolutionary paradox of sex. BioEssays, 33(12), 927-937. http://doi.org/10.1002/bies.201100096

822 Wickham, H. (2009). ggplot2 elegant graphics for data analysis. Springer-Verlag New York. http://doi.org/10.1007/978-0-387-98141-3

824 
827 Figure 1: The nine enclosures are depicted as black rectangles with their number between 828 parentheses (enclosure \#7 was not used). Circles represent colonies. In each enclosure, the 829 two circles at the top of the rectangle are the two transplanted colonies. The red and crowned 830 circle is the queenright colony and the green circle is the orphaned colony (\# identify the two 831 colonies that were collected queenless). Queenright and orphaned colonies were identified by 832 the presence of the queen and by their large production of gynes, respectively. Smaller circles 833 show propagules with the same colour than their mother colony (as determined by genetic 834 analysis, see Results). The areas of circles are proportional to colony size at the time of 835 recollection, and are standardised relative to the largest nest within each enclosure. The 836 number of sexuals collected in each colony is given in light orange for gynes, light and dark 837 blue for haploid and diploid males, respectively (all diploid males were produced by 838 thelytoky), and grey for foreign males. All sexuals from queenright colonies were produced 839 asexually by the queen except in enclosure 4 where they were non clonal $(*)$ and where seven 840 were worker-produced, including three originating from the queenless nest. $* *$ shows worker841 produced gynes.

844 Figure 2: Worker loss ratio (a) and gynes production (b) in queenright (QR) and queenless 845 (QL) colonies. Worker loss ratio is the ratio of the number of workers lost during the 11 846 weeks spent in the enclosures divided by the initial colony size. Each dot represents one 847 enclosure labelled with its number (enclosure \#7 was not used). Dotted lines correspond to an 848 equal ratio of worker loss and of gyne production, i.e. dots below the lines correspond to 849 enclosures where QR colonies had higher worker loss (a) or higher gyne production (b) than 850 QL colonies (and conversely above the lines). 
851 Figure 3: Distribution of patrilines in workers (dark grey) and gynes (light grey) for the eight 852 orphaned colonies and for the queenright colony of enclosure 4. The data are depicted as the 853 number of workers or gynes for each nest. The probability value of the Fisher test testing the 854 null hypothesis of no difference in patrilines distribution is given between parentheses in the 855 title for each nest. In nest 4-QR-a, patriline 4AP1 (marked with ****) corresponds to patriline 8561 of neighbouring nest 4-QL-a.

857

858 
859 Table A1: Size and composition of colonies.

\begin{tabular}{|c|c|c|c|c|c|}
\hline & & Workers & Workers & Worker & Sexuals \\
\hline Enclosure & Nests & implanted & recollected & genotyped & recollected \\
\hline \multirow[t]{5}{*}{1} & QRa & $\mathbf{1 , 5 7 0}$ & 824 & $\mathbf{0}$ & 86 \\
\hline & QLa & 1,868 & 465 & 20 & 66 \\
\hline & QLb & & 167 & 2 & 1 \\
\hline & QLc & & 61 & 2 & 1 \\
\hline & QLd & & 82 & 2 & 0 \\
\hline \multirow[t]{3}{*}{2} & QRa* & 884 & 632 & $\mathbf{0}$ & $\mathbf{0}$ \\
\hline & $\mathbf{Q R b}$ & & 448 & 2 & 7 \\
\hline & QLa & 1,298 & 665 & 20 & 75 \\
\hline \multirow[t]{5}{*}{3} & QRa & 886 & 484 & $\mathbf{0}$ & 52 \\
\hline & $\mathbf{Q R b}$ & & 38 & 2 & 2 \\
\hline & $\mathrm{QLa}^{\#}$ & 960 & 277 & 20 & 36 \\
\hline & QLb & & 45 & 2 & 2 \\
\hline & QLc & & 60 & 2 & 1 \\
\hline \multirow[t]{2}{*}{4} & QRa & 652 & 267 & 20 (1 from $A-Q L)$ & 12 \\
\hline & QLa & 682 & 320 & 20 & 6 \\
\hline \multirow[t]{4}{*}{5} & QRa & 505 & 221 & $\mathbf{0}$ & 5 \\
\hline & QRb & & 53 & 2 & 1 \\
\hline & QLa & 1,048 & 462 & 21 & 67 \\
\hline & QLb & & 9 & 2 & 0 \\
\hline \multirow[t]{2}{*}{6} & QRa & 606 & 410 & 0 & 0 \\
\hline & $\mathrm{QLa}^{\#}$ & 427 & 135 & 20 & 13 \\
\hline 8 & QRa & 1,760 & 1073 & 0 & 41 \\
\hline
\end{tabular}




\begin{tabular}{|c|c|c|c|}
\hline QLa & 2,101 & 298 & 23 (1 foreign) \\
\hline QLb & & 433 & 2 \\
\hline QLc & & 41 & 2 \\
\hline QLd & & 13 & 2 \\
\hline QRa & 511 & 298 & 0 \\
\hline QLa & 564 & 309 & 20 \\
\hline QRa & 429 & 269 & 0 \\
\hline QLa & 562 & 290 & 20 \\
\hline
\end{tabular}

860 The table gives the number of workers implanted in enclosures in March (enclosure \#7 was

861 not used), recollected from enclosures in May and genotyped, as well as the number of

862 sexuals collected (all sexuals were genotyped). Nests recollected in enclosures were assigned

863 to the corresponding implanted queenright (QR) or queenless (QL) colony based on the

864 presence of the marked queen or on the genetic analysis of workers (see M\&M). Queenright

865 colonies and the new nests they produced are highlighted in bold. * this nest was not found in

866 may but collected in September. \# these nests were collected orphaned.

867 
Table A2: genotypes of the queens of nests 4QRa and 4QLa, of their mates inferred from worker genotypes, and of the 10 gynes produced by nest 4QRa.

\begin{tabular}{|c|c|c|c|c|c|c|c|c|c|}
\hline Individuals & L46 & L51 & L11 & L58 & L61 & L99 & L100 & L65 & origin \\
\hline Mate1 & 153 & 216 & 235 & 150 & 265 & 128 & 195 & 248 & \\
\hline Mate2 & 153 & 206 & 235 & 171 & 253 & 128 & 177 & 248 & \\
\hline Mate3 & 153 & 198 & 235 & 150 & 217 & 130 & 193 & 256 & \\
\hline Mate4 & 157 & 204 & 235 & 150 & 241 & 118 & 193 & 248 & \\
\hline Mate5 & 153 & 196 & 235 & 150 & 225 or 245 & 130 & 193 & 256 & \\
\hline Mate6 & 161 & 188 & 239 & 171 & 251 & 126 & 177 & 250 & \\
\hline Gyne G9 & $157 / 157$ & $198 / 200$ & $235 / 235$ & $165 / 178$ & $? / ?$ & 118/118 & 191/191 & $248 / 250$ & $4 Q \mathrm{~L}$ mate 3 \\
\hline Gyne G11 & $153 / 153$ & $196 / 198$ & $235 / 259$ & $165 / 178$ & $231 / 243$ & $118 / 130$ & 191/195 & $246 / 248$ & 4QL mate1 \\
\hline Gyne G10 & $\underline{161 / 161}$ & $198 / 216$ & $235 / 245$ & $150 / 150$ & $? / ?$ & $126 / 128$ & $189 / 195$ & $248 / 248$ & $\underline{4 Q R}$ mate 1 \\
\hline
\end{tabular}




$\begin{array}{cccccccccc}\text { Gyne G2 } & 155 / 161 & 196 / 198 & \underline{245 / 245} & 150 / 150 & 225 / 255 & 126 / 126 & 189 / 191 & 248 / 250 & \underline{4 Q R} \text { mate7 } \\ \text { Gyne G4 } & 153 / 161 & 198 / 216 & 235 / 245 & 150 / 150 & 255 / 265 & \underline{128 / 128} & 193 / 195 & 248 / 248 & \underline{4 Q R} \text { mate1 } \\ \text { Gyne G5 } & 153 / 161 & 196 / 216 & \underline{225 / 225} & 150 / 150 & 255 / 265 & 126 / 128 & 193 / 195 & 248 / 248 & \underline{4 Q R ~ m a t e 1} \\ \text { Gyne G6 } & 157 / 161 & 196 / 204 & 225 / 235 & 150 / 150 & 241 / 255 & 118 / 126 & 189 / 193 & 248 / 248 & 4 Q R \text { mate4 } \\ \text { Gyne G7 } & \underline{161 / 161} & 198 / 216 & 235 / 245 & 150 / 150 & ? / ? & 126 / 128 & 193 / 195 & 248 / 248 & \underline{4 Q R ~ m a t e 1} \\ \text { Gyne G8 } & 153 / 161 & 198 / 216 & 235 / 245 & 150 / 150 & 245 / 265 & 126 / 128 & 193 / 195 & 248 / 248 & 4 Q R \text { mate1 }\end{array}$

\section{Nest 4QLa}

$\begin{array}{lllllllll}\text { Queen } & 153 / 157 & 196 / 198 & 235 / 259 & 165 / 171 & 243 / 253 & 118 / 118 & 185 / 191 & 250 / 246 \\ \text { Mate1 } & 161 & 198 & 235 & 178 & 231 & 130 & 195 & 248 \\ \text { Mate2 } & 157 & 200 & 235 & 178 & 233 & 118 & 191 & 248 \\ \text { Mate3 } & 157 \text { or } 153 & 196 & 235 & 150 & 253 & 118 & 193 & 248 \\ \text { Mate4 } & 153 & 200 & 235 & 150 & 233 & 138 & 193 & 248 \\ \text { Mate5 } & 157 \text { or } 153 & 196 \text { or } 198 & 235 \text { or } 239 & 150 & 255 & 116 & 193 & 250 \text { or } 246\end{array}$

870 All gynes were sexually produced. Three were daughters of workers from the queenless nest 4QLa (highlighted in bold), five were probably

871 produced by workers of the queenright nest $4 \mathrm{QRa}$, and two could have been produced either sexually by the queen or by workers of the

872 queenright nest 4QRa. The homozygous genotypes showing that gynes were probably parthenogenetically produced by workers are underlined. 